\title{
ANSWER TO KIRK-SHAHZAD'S QUESTION ON ZHANG-JIANG'S FIXED POINT THEOREM
}

\author{
NGUYEN VAN DUNG \\ Faculty of Mathematics and Information Technology Teacher Education \\ Dong Thap University, 783 Pham Huu Lau Street, Ward 6 \\ Cao Lanh City, Dong Thap Province, Viet Nam \\ E-mail: nvdung@dthu.edu.vn
}

\begin{abstract}
In this note we give a positive answer to Kirk-Shahzad's question on Zhang-Jiang's fixed point theorem [8, Question on page 18].

Key Words and Phrases: Partial order, Brézis-Browder order principle, fixed point.

2010 Mathematics Subject Classification: 47H10, 54H25, 54F05.
\end{abstract}

Acknowledgment. The author is greatly indebted to anonymous reviewers for their helpful comments, especially in proving the maximal element $x^{*}$ of $\left(X_{\delta}, \preceq\right)$ is a fixed point of $f$.

\section{REFERENCES}

[1] H. Brézis, F.E. Browder, A general principle on ordered sets in nonlinear functional analysis, Adv. Math., 21(1976), 355-364.

[2] N. Brunner, Topologische maximalprinzipien, MLQ Math. Log. Q., 33(1987), no. 2, 135-139 (in German).

[3] J. Caristi, Fixed point theorems for mappings satisfying inwardness conditions, Trans. Amer. Math. Soc., 215(1976), 241-251.

[4] J. Caristi, W.A. Kirk, Geometric fixed point theory and inwardness conditions, The Geometry of Metric and Linear Spaces, vol. 490, pp. 74-83, Springer Berlin Heidelberg, 1975.

[5] I. Ekeland, Sur les problemes variationnels, C.R. Acad. Sci. Paris Sér. A-B, 275(1972), A1057A1059.

[6] I. Ekeland, On the variational principle, J. Math. Anal. Appl., 47(1974), no. 2, 324-353.

[7] K. Goebel, W. A. Kirk, Topics in Metric Fixed Point Theory, Cambridge Univ. Press, 1990.

[8] W. Kirk, N. Shahzad, Fixed Point Theory in Distance Spaces, Springer, Cham, 2014.

[9] W.A. Kirk, L.M. Saliga, The Brézis-Browder order principle and extensions of Caristi's theorem, Nonlinear Anal., 47(2001), no. 4, 2765-2778.

[10] R. Manka, Some forms of the axiom of choice, Jahrb. Kurt-Gödel-Ges., 1(1988), 24-34.

[11] G. Zhang, D. Jiang, On the fixed point theorems of Caristi type, Fixed Point Theory, 14(2013), no. $2,523-529$.

Received: October 8, 2015; Accepted: November 28, 2016. 